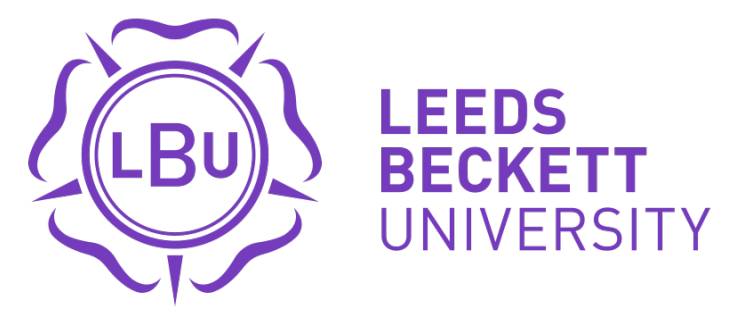

Citation:

Manley, A and Greenlees, I and Thelwell, R and Smith, M (2010) Athletes' use of reputation and gender information when forming initial expectancies of coaches. International Journal of Sports Science and Coaching, 5 (4). 517 - 532. ISSN 1747-9541 DOI: https://doi.org/10.1260/1747-9541.5.4.517

Link to Leeds Beckett Repository record:

https://eprints.leedsbeckett.ac.uk/id/eprint/319/

Document Version:

Article (Accepted Version)

The aim of the Leeds Beckett Repository is to provide open access to our research, as required by funder policies and permitted by publishers and copyright law.

The Leeds Beckett repository holds a wide range of publications, each of which has been checked for copyright and the relevant embargo period has been applied by the Research Services team.

We operate on a standard take-down policy. If you are the author or publisher of an output and you would like it removed from the repository, please contact us and we will investigate on a case-by-case basis.

Each thesis in the repository has been cleared where necessary by the author for third party copyright. If you would like a thesis to be removed from the repository or believe there is an issue with copyright, please contact us on openaccess@leedsbeckett.ac.uk and we will investigate on a case-by-case basis. 
Running head: Expectancy formation in the coach-athlete relationship

\title{
Athletes' use of reputation and gender information when forming initial expectancies of coaches
}

\author{
Andrew J. Manley* \\ Iain A. Greenlees \\ Leeds Metropolitan University, \\ University of Chichester, \\ Carnegie Faculty of Sport \& Education, \\ Faculty of Sport, Education \& Social \\ Fairfax Hall, \\ Sciences, \\ Headingley Campus, \\ College Lane, \\ Leeds, U.K. \\ Chichester, U.K. \\ Richard C. Thelwell \\ Matthew J. Smith \\ University of Portsmouth, \\ University of Chichester, \\ Department of Sport \& Exercise Science, \\ Faculty of Sport, Education \& Social \\ Spinnaker Building \\ Sciences, \\ Cambridge Road, \\ College Lane, \\ Portsmouth, U.K. \\ Chichester, U.K.
}

*Please address correspondence to: Andrew Manley, Carnegie Faculty of Sport and Education, Leeds Metropolitan University, Fairfax Hall, Headingley Campus, Leeds, West Yorkshire, LS6 3QS, U.K.

Tel: 0113812 4717; E-mail: A.J.Manley@leedsmet.ac.uk

Submitted: August 2009

Resubmitted: June 2010 
Running head: Expectancy formation within the coach-athlete relationship

Athletes' use of reputation and gender information when forming initial expectancies of coaches 


\begin{abstract}
The study aimed to investigate the impact of coach reputation and gender on athletes' expectancies of coaching competency. Male and female athletes $(n=304)$ viewed a coach profile (i.e., photograph and brief description of the target coach) before being asked to rate their expectancies of the coach's competency. Gender and reputation (i.e., successful vs. unsuccessful) of the target coach were manipulated. Multivariate and follow-up univariate analyses of variance revealed that successful coaches were rated as significantly more competent than unsuccessful coaches, while the female target coach was rated as significantly less competent than the male target coach on some competency dimensions. Athletes also reported that reputation influenced their expectancies more than gender. These findings indicate that athletes' expectancies of coaching competency are influenced by the coach’s reputation and gender, although this impact appears to be more pronounced for reputation. Such results have implications for the development of effective coach-athlete relationships.
\end{abstract}

Key words: person perception, first impressions, informational cues, expectancy formation, coach-athlete relationship. 
Athletes' use of reputation and gender information when forming initial expectancies of coaches

\section{INTRODUCTION}

Categorised as beliefs about a future state of affairs [1], expectancies represent the process of utilising observable cues, past experience and knowledge in order to predict specific outcomes and develop a set of rules about the world. Expectancies in social interactions not only allow the perceiver to make sense of the target and themselves, but also help people to make predictions about the ensuing interactions [2]. Expectancies have been proposed to play a major role in everyday social encounters, and have the potential to influence the cognitive, affective, and behavioural responses exhibited during interpersonal interaction [1,3].

In the sport setting, interpersonal interaction is inevitable. People involved in sport (e.g., athletes, coaches, officials) often find themselves in social situations where the formation of interpersonal expectancies (i.e., expectancies of others) provides a way of managing subsequent interactions. During encounters between competing athletes, expectancies based on available information may to facilitate the achievement of performance goals. For example, prior to a penalty kick in football, the goalkeeper may enhance his or her chances of saving the penalty by engaging in a process often referred to as anticipation [4]. This involves the goalkeeper creating an expectancy of where the shot will go based on specific cues that are deemed to be relevant (e.g., the position of the opposing kicker's non-kicking foot). Expectancies can also be employed by individuals in order to aid the development of effective cooperative relationships. Thus, by making a prediction about how a target individual (e.g., teammate, colleague, opponent) is likely to think, feel, or behave, the perceiver is better able to select an appropriate response in an attempt to achieve the most 
effective outcome from the interaction. One important sporting alliance that may be influenced by interpersonal expectancies is the coach-athlete relationship.

The importance of examining the effect of expectancies on interactions between coaches and athletes is largely due to the highly interdependent nature of this relationship. Jowett and Poczwardowski [5] define the coach-athlete relationship as “a situation in which a coach’s and an athlete’s cognitions, feelings, and behaviours are mutually and causally interrelated” (p.4). According to this definition, the coachathlete relationship is dynamic in nature, and is shaped by the interactions that occur between the members within it. The importance of the coach-athlete relationship is exemplified within Becker's [6] Model of Great Coaching. According to Becker, the development and consistent maintenance of effective personal and professional relationships with athletes is a central component of great coaching. Given that expectancies have the potential to significantly impact on the cognitive, affective, and behavioural consequences of social encounters [1], it follows that expectancies may be important determinants of the way in which the affiliation between coach and athlete is allowed to develop and function. Specifically, the expectancies that are held, exhibited, and responded to by coaches and athletes could have positive and negative impacts on performance and psychological well being within such an interdependent relationship. As a result, expectancy effect research within the context of the coach-athlete relationship is crucial to the generation of knowledge that may enable coaches and athletes to satisfactorily manage their interpersonal interactions, thus allowing for the development of an effective working alliance.

The bulk of research regarding the formation and impacts of expectancies as a result of coach-athlete interaction has focused solely on the examination of coach expectancies and behaviours. For example, work conducted in youth sport $[7,8]$ and at the collegiate level $[9,10,11]$ has demonstrated that coaches' expectancies of 
athletes' abilities can influence the feedback behaviour exhibited by the coach. There have also been attempts to classify the sources of information used by coaches when forming impressions and expectancies of athletes [12,13,14]. However, Smoll and Smith [15] identified that "the ultimate effects that coaching behaviour exerts are mediated by the meaning that players attribute to them” (p.1527). Horn [16] agreed that the influence of coach behaviour on athletes' attitudes, self-perception, and performance is partly mediated by athletes' evaluations and expectancies of the coach, and argued that by understanding how athletes form impressions and expectancies, coaches will be in a position to utilise their own behaviour as a beneficial tool. Despite these realisations, there is little research to date that has examined expectancy effects within the coach-athlete relationship from the perspective of the athlete.

There has, however, been an initial effort to identify and categorise the informational cues athletes deem influential when forming initial expectancies of a coach. In a recent explorative study, Manley, Greenlees, Graydon, Thelwell, Filby, and Smith [17] asked a sample of 534 athletes to rate the perceived influence of various informational cues on the development of their expectancies of a coach. The results provided a preliminary three-factor model for the types of cues athletes use as a basis for the formation of coach-referent expectancies. The model suggests that while athletes perceive dynamic cues (e.g., body language, facial expressions) and third-party reports (e.g., reputation, coaching experience) to be highly influential sources of information during expectancy formation, static cues (e.g., gender, age, race/ethnicity) are seen by athletes to have less of an impact on the expectancies they form of coaches. Thus, the study by Manley et al. led to the extraction of third-party reports as a distinct category of information sources that may be used by athletes when developing expectancies of a coach. This is in line with Olson et al.’s [1] model of expectancy processes, which proposes that expectancies may be based on indirect 
experience in the form of the beliefs of other people (i.e., third-parties). Moreover, Manley et al.'s findings concur with initial evidence to support the notion that thirdparty reports such as reputation can impact on the expectancies formed by sports personnel such as judges [18], referees [19], and coaches [20]. However, given that third-party reports have only recently been identified as a stand-alone category of information sources that may be used in the formation of expectancies, their influence on the creation of athletes' initial expectancies of coaches is worthy of further investigation. Thus, the first aim of the present study is to discover the extent to which athletes' expectancies of coach competency are influenced by third-party reports via the manipulation of coach reputation (i.e., successful vs. unsuccessful). In light of evidence from previous research $[17,18,19]$, it is hypothesised that athletes will provide significantly more favourable ratings of coaching competency for targets who have a successful reputation as opposed to an unsuccessful reputation.

The extent to which static cues impact on expectancy formation in the coachathlete relationship also warrants further clarification. Although the findings of Manley et al. [17] have provided additional support for the contention that expectancies based on dynamic behavioural cues are more influential and have greater predictive validity than expectancies founded on static sources of information $[10,13,21,22]$, previous research has demonstrated the importance of static cues in expectancy formation. In sport settings, informational cues such as gender [23], race [24], and physique $[25,26]$ have been shown to shape perceivers' expectancies of a target, suggesting that static cues may also influence expectancy formation.

With specific reference to athletes' perceptions of coach gender, previous research indicates that both male and female athletes prefer to be coached by men [27]. Other researchers have attributed this trend to the stereotypic belief that it is not appropriate for women to participate in sport, especially when it comes to sports such 
as soccer, which are traditionally perceived by both men and women as masculine or male-oriented [28,29]. More recently, however, Riemer and Visio [30] found that adolescent male and female athletes perceived soccer as a neutral sport in terms of its gender-orientation. This finding supports the view that the traditional stigmas associated with female sport participation may be slowly changing, and that sport is starting to be perceived equally as a male and female domain [31,32]. Despite such indications, there remains evidence that reinforces traditional sex role stereotypes in sport. For example, Kontos [33] reported that in cross-gender coach-athlete relationships, female coaches were perceived to engage in more negative coaching behaviours (e.g., punishing players, ignoring mistakes) than male coaches. The above findings indicate that static informational cues such as gender have the potential to influence athletes' expectancies of sporting individuals, despite suggestions that expectancy effects as a function of gender are beginning to become less prevalent $[30,31,32]$.

Given the above debate, the second aim of the present study is to examine the degree to which the gender of the coach influences athletes' expectancies. Following reports from previous research examining the effect of gender on coach-athlete relationships [27,33], it is hypothesised that both male and female athletes will evaluate female coaches less favourably than male coaches. A third purpose of the present study is to examine athletes' perceived influence of coach gender and coach reputation on the formation of their initial expectancies of an unknown coach. In line with the findings of Manley et al. [17], it is hypothesised that athletes will perceive gender to have less of an impact than reputation on the expectancies they develop of the target coach, and that these ratings of perceived influence will not differ significantly between male and female athletes. 
In summary, the main hypotheses of the study state that: $\left(\mathrm{H}_{1}\right)$ coaches with a successful reputation will be rated as significantly more competent than coaches with an unsuccessful reputation; $\left(\mathrm{H}_{2}\right)$ female coaches will be evaluated as significantly less competent than male coaches, regardless of athlete gender; and $\left(\mathrm{H}_{3}\right)$ both male and female athletes will perceive coach reputation to be a more influential source of information than coach gender when forming initial expectancies of coaching competency. It is hoped that the findings will provide valuable information for sports coaches that may help them manage their behaviour with a view to facilitating effective coach-athlete relationships.

\section{METHOD}

\section{Participants}

A total of 384 athletes, recruited from amateur and British university sports teams, volunteered to take part in the present study. However, 71 volunteers did not fully complete the questionnaire and their data were excluded from the analysis. Preliminary analysis of the data for testing assumptions revealed that Box's $M$ test was significant at $p<.001$. In addition, the groups with smaller sample sizes produced greater variances and covariances than the larger sample groups, indicating that probability values would be liberal and, as a result, any significant differences would need to be treated with caution [34]. In the event that probabilities cannot be trusted, such as is evident here, Field [35] recommends that the sample sizes should be equalised through the random deletion of cases from the larger groups. Thus, in order to ensure equal group sizes for each experimental condition $(n=38)$, a further nine cases were randomly selected from the groups with the largest samples and omitted from the overall analysis. The remaining 304 participants (Mean age $=21.31$ years, $\mathrm{SD}=3.31)$ consisted of 152 males and 152 females, with a mean of 8.88 years $(\mathrm{SD}=$ 
4.66) experience in their primary sport. Athletes were predominantly White Caucasian (95.6\%), with the remainder made up of Black (1.7\%), Asian (1.2\%), and Mixed Race (1.5\%) participants. A total of eight sports were represented by the population sample, including football/soccer (30.3\%), ultimate frisbee (27.3\%), rugby union (15.1\%), netball (9.9\%), field hockey (8.2\%), cricket (4.3\%), basketball (3.0\%), and volleyball (2.0\%). The majority of athletes reported their highest level of participation to be at either university/club level (48.4\%), or while representing their region or county (43.8\%). A total of 24 participants (7.9\%) had experience at either the national or professional level.

Materials

Participants viewed and rated a total of two coach profiles: one control coach profile and one of four experimental coach profiles. Each coach profile consisted of a greyscale photograph of the target coach accompanied by a brief written description. In light of the recommendation by Johnson, Hallinan, and Westerfield [36] that “...the use of photographs and rotated descriptors can provide a useful device for eliciting the underlying localised assumptions which may be attributed to various population groups” (p.52), photographs and written descriptions were deemed to be suitable stimulus objects for the present study. Each description informed participants of the target coach’s name, age, gender, coaching experience, coaching qualifications, and reputation (successful vs. unsuccessful). All descriptions were based on a template used by Greenlees, Webb, Hall, and Manley [37], with details altered to include information specific to coach reputation. The description of the successful coach was as follows:

"[Paul/Susan] is a 25-year-old coach from London. [He/She] has been a fulltime coach for 6 years. [Paul/Susan] holds a number of recognised coaching 
qualifications. [He/She] has worked with athletes of varying age and ability, ranging from novice children to elite-level adults. During [his/her] coaching career, [Paul/Susan] has won a number of honours with both amateur and semi-professional teams, and the team [he/she] coached last season won their regional cup competition. [Paul/Susan] is enthusiastic about [his/her] sport and enjoys [his/her] job.”

The description of the unsuccessful coach was exactly the same as above, except that the penultimate sentence was altered to read:

“During [his/her] coaching career, [Paul/Susan] has not won any honours with the teams [he/she] has worked with, and the team [he/she] coached last season was ultimately relegated.”

The profile of the control target (i.e., male) was similar to the experimental profiles, but there was no mention of reputation information within the written description. The control coach was included as a means of demonstrating that when reputation and gender were not manipulated, athletes' expectancies of the target coach were not significantly different between experimental groups.

Pilot testing was conducted to ensure that there were no significant differences between the experimental profile photographs, with no reputation differences, in terms of perceived age, attractiveness, coaching experience, body language, build/physique, and perceived friendliness. Since these factors had the potential to act as confounding variables $[10,38,39]$, it was vital that their potential influence on the athletes' expectancies of the coaches was accounted for. A sample of male $(n=28)$ and female $(n=28)$ athletes from the University of the first author (Mean age $=23.34$ years, $\mathrm{SD}=3.98$; Mean sport experience $=10.24$ years, $\mathrm{SD}=4.89$ ) volunteered to participate in the pilot testing. Participants rated each photograph in terms of the six target characteristics using 5-point Likert scales ( $1=$ low rating; $5=$ high rating). A 2 
(Participant gender) x 2 (Target gender) mixed model analysis of variance (ANOVA) revealed that there were no significant main effects for participant gender $\left(F_{1,52}=\right.$ 2.09, $\left.p=.15, \eta^{2}=.04\right)$ or target gender $\left(F_{1,52}=.07, p=.79, \eta^{2}=.00\right)$. Moreover, no significant interaction effects were reported: participant gender $\mathrm{x}$ target gender, $F_{1,52}$

$=0.85, p=.36, \eta^{2}=.02$; participant gender $\mathrm{x}$ target characteristic, $F_{3.59,186.65}=1.18, p$ $=.32, \eta^{2}=.02$; target gender $\mathrm{x}$ target characteristic, $F_{3.59,186.65}=1.49, p=.21, \eta^{2}=$ .03 ; participant gender $\mathrm{x}$ target gender $\mathrm{x}$ target characteristic, $F_{3.59,186.65}=0.24, p=$ $\left..90, \eta^{2}=.01\right)$

Measures

Athlete demographic questionnaire.

Background information of athletes was obtained via athlete demographic questionnaires. Athletes' age, gender, race/ethnicity, primary sport, number of years experience in primary sport, team(s) they currently represented, and highest level of participation were obtained.

Adapted Coaching Competency Scale (CCS-A).

An adapted version of the Coaching Competency Scale (CCS) [40], was developed as a means of examining athletes' expectancies of coaches following the provision of initial information. The original scale consists of 24 statement items, which measure four key areas of coaching competency: motivation competency (i.e., the ability to affect the psychological mood and skills of athletes), game strategy competency (i.e., the ability to select and execute appropriate competitive strategies), character-building competency (i.e., the ability to instil positive attitudes and influence athletes’ personal development), and technique competency (i.e., the ability to teach the athlete in terms of skill development). Participants are asked to use each 
item to complete the following sentence: "How competent is your head coach in his or her ability to ?”

Myers and colleagues [40,41] have provided evidence for the reliability and validity of the CCS, although this only extends to studies involving high school and collegiate athletes participating in team sports. However, since the population sample within the present study satisfies these criteria, the adapted version of the CCS was deemed to be a useful tool in the examination of athlete expectancies regarding their coach. Myers et al. [40] also reported that motivation competency (i.e., athletes’ evaluations of their coach's ability to affect athletes’ psychological mood and skill) had a moderately large and positive relationship with athletes' satisfaction with the coach within teams. In addition, Myers et al. [41] suggested that "studies that investigate...how a coach's behaviour influences athletes’ perceptions of their coach’s competency could advance understanding in coaching effectiveness and extend validity evidence for the CCS” (p. 461-462). Thus, inclusion of the adapted CCS as an assessment item within the present study was considered appropriate. Since the participants in the present study were presented with profiles of coaches who were unknown to them, the sentence of the original CCS was altered to read: "I believe that this coach would ”. Participants provided ratings for all items using a 7-point Likert scale (e.g., $1=$ Very strongly disagree to $7=$ Very strongly agree), and were asked to base their ratings on the premise that the target coach had recently been appointed as the new head coach for their team. Perceived influence questionnaire.

A post-experimental questionnaire was included to examine which of the manipulated cues athletes believed had the greatest influence over the expectancies they developed about the target coach. Athletes’ perceptions of the influence of each of the independent variables on their expectancy formation were measured by a 
method similar to that used by Lubker et al. [25]. After rating the coaches, participants were asked to rate the extent to which they believed each of the independent variables (i.e., gender and reputation) had influenced the expectancies they had formed of the target coaches. Perceived influence was indicated using 5point Likert scales (e.g., $1=$ Not at all influential to $5=$ Extremely influential).

Procedure

Participants were approached and recruited at various amateur and university sports events over a period of approximately three months. Participants were provided with the test battery, which consisted of a consent form, athlete demographic questionnaire, control coach profile, one of the four experimental coach profiles (i.e., male-successful; male-unsuccessful; female-successful; female-unsuccessful), two copies of the adapted Coaching Competency Scale (CCS-A; one for each coach profile), and the perceived influence questionnaire. Athletes were asked to carefully study and rate their expectancies of each coach profile separately. The questionnaires were completed in the presence of the first author (or a fully briefed assistant) so that any queries from participants could be answered. The questionnaires took around 10 minutes to complete. Once athletes had completed the test battery, they were fully debriefed and thanked for their participation. The study was carried out in line with the institutional ethics procedures of the university of the first author.

\section{Data Analysis}

Preliminary analysis.

In order to assess the dependent variables for multicollinearity, Pearson product-moment correlations were conducted. Multicollinearity (i.e., an indication that two dependent variables are measuring the same construct) was assumed for 
correlations greater than .80 [42]. In the event of multicollinearity, the two dependent variables would be combined to form a single variable, again following the recommendation of Stevens [42].

Main analyses.

Multivariate analysis of variance (MANOVA) and follow-up univariate analysis of variance (ANOVA) tests were performed on subscale scores obtained from the CCS-A with the aim of testing hypotheses one and two (i.e., identifying any differences in ratings that may have occurred as a result of manipulation of coach gender, and coach reputation). Eta squared $\left(\eta^{2}\right)$ effect sizes were also computed. In line with the recommendations of Clark-Carter [43], effect sizes of between .001 and .058 were classified as small, effect sizes of between .059 and .137 classified as medium, and effect sizes of .138 and over were classified as large. A mixed model ANOVA was conducted on responses to the perceived influence questionnaire in order to test hypothesis three (i.e., identify which of the independent variables athletes believed had the greatest impact on expectancy formation, whilst also accounting for any differences as a function of participant gender).

\section{RESULTS}

Descriptive Statistics

Mean scores and standard deviations of athletes’ ratings of the experimental coach are displayed in Table 1.

INSERT TABLE 1 HERE

Preliminary Analysis 
Analysis of Pearson product-moment correlations revealed that no relationship exceeded Stevens' [42] multicollinearity criterion value of .80. As a result, all items were included in the subsequent analyses.

\section{Main Analyses}

Ratings of coach competence.

Two separate 2 (Participant gender) x 2 (Coach gender) x 2 (Reputation) MANOVAs were conducted to see whether there were any significant differences in athletes' ratings of the control coach and the experimental coach between the eight experimental conditions. Since Box's $M$ tests indicated significant differences in the covariance matrices of the dependent variables $(p<.05)$, Pillai's trace was used as the criterion value in the analyses that followed.

A significant main effect was found for participant gender on ratings of the control coach, Pillai's trace $4,293=0.07, F=5.80, p<.001, \eta^{2}=.07$, observed power $=.98$. Follow-up ANOVAs revealed that female athletes rated the control target significantly higher than did male athletes on motivation competency $\left(F_{1,296}=4.24, p\right.$ $=.04, \eta^{2}=.01$, observed power $\left.=.54\right)$, game strategy competency $\left(F_{1,296}=13.13, p<\right.$ $.001, \eta^{2}=.04$, observed power $\left.=.95\right)$, character-building competency $\left(F_{1,296}=9.74, p\right.$ $=.002, \eta^{2}=.03$, observed power $\left.=.88\right)$, and technique competency $\left(F_{1,296}=6.06, p=\right.$ $.01, \eta^{2}=.02$, observed power $=.69$ ). However, no other significant main effects or interaction effects were found. Thus, the observed differences are limited to participant gender and do not extend to include target gender or reputation. In other words, when participants were of the same gender, expectancies of the control coach's level of competency were the same across all experimental conditions.

A significant main effect was found for reputation on ratings of the experimental coach, Pillai's trace ${ }_{4,293}=0.43, F=54.61, p<.001, \eta^{2}=.43$, observed 
power $=1.00$. In line with hypothesis one, follow-up ANOVAs revealed that coaches with a successful past record were rated significantly higher than coaches with an unsuccessful past record on motivation competency $\left(F_{1,296}=111.06, p<.001, \eta^{2}=\right.$ .27 , observed power $=1.00)$, game strategy competency $\left(F_{1,296}=205.88, p<.001, \eta^{2}\right.$ $=.41$, observed power $=1.00)$, character-building competency $\left(F_{1,296}=15.26, p<\right.$ $.001, \eta^{2}=.05$, observed power $\left.=.97\right)$, and technique competency $\left(F_{1,296}=103.87, p<\right.$ $.001, \eta^{2}=.26$, observed power $\left.=1.00\right)$. A significant main effect was also observed for target gender on ratings of the experimental coach, Pillai's trace $4,293=0.04, F=$ 3.15, $p=.02, \eta^{2}=.04$, observed power $=.82$. As predicted by hypothesis two, follow-up ANOVAs revealed that the female coach was rated significantly worse than the male coach on game strategy competency $\left(F_{1,296}=6.49, p=.01, \eta^{2}=.02\right.$, observed power $=.72)$, and technique competency $\left(F_{1,296}=10.63, p=.001, \eta^{2}=.04\right.$, observed power $=.90)$. No significant main effect was found for participant gender, Pillai's trace $4,293=0.02, F=1.34, p=.26, \eta^{2}=.02$, observed power $=.42$.

A significant target gender $\mathrm{x}$ reputation interaction effect was found for ratings of the experimental coach, Pillai's trace $4,293=0.03, F=2.58, p=.04, \eta^{2}=.04$, observed power $=.72$. However, follow-up ANOVAs did not reveal any significant effects for character-building competency $\left(F_{1,296}=1.08, p=.30, \eta^{2}=.00\right.$, observed power $=.18)$; game strategy competency $\left(F_{1,296}=0.02, p=.88, \eta^{2}=.00\right.$, observed power $=.05)$; motivation competency $\left(F_{1,296}=2.21, p=.14, \eta^{2}=.01\right.$, observed power $=.32)$; or technique competency $\left(F_{1,296}=1.77, p=.18, \eta^{2}=.01\right.$, observed power $=$ .26). This indicates that while reputation and gender combine to have an effect on athletes' overall expectancies of coaching competency, the two independent variables do not contribute to a significant change in athletes' ratings when each of the four specific coaching competencies are examined separately [44]. 
Scrutiny of the mean scores displayed in Table 1 suggests that when the coach was male and had a successful reputation, he was perceived to be more competent than when the coach had an unsuccessful reputation, regardless of whether they were male or female. In addition, the mean scores indicate that when the coach was female and successful, athletes perceived her to be more competent than a coach who was either male and had an unsuccessful reputation, or female and had an unsuccessful reputation. There were no other significant interaction effects between the independent variables for the experimental coach: participant gender $\mathrm{x}$ target gender, Pillai's trace ${ }_{4,293}=0.02, F=1.11, p=.35, \eta^{2}=.02$, observed power $=.35$; participant gender $x$ reputation, Pillai's trace ${ }_{4,293}=0.02, F=1.26, p=.29, \eta^{2}=.02$, observed power $=.39$; participant gender $\mathrm{x}$ target gender $\mathrm{x}$ reputation, Pillai's trace 4 , $293=0.02, F=1.27, p=.28, \eta^{2}=.02$, observed power $=.40$.

Ratings of perceived influence.

A 2 (Participant gender) x 2 (Coach characteristic) mixed model ANOVA (with repeated measures on the second factor) was conducted to discover (a) the extent to which athletes believed that coach gender and reputation influenced their subsequent expectancies of the target coach, and (b) if there was any difference between male and female athletes in terms of the importance they attached to coach gender and reputation as sources of information. Mean ratings are displayed in Figure 1. A significant main effect was found for coach characteristic, $F_{1,302}=464.18, p<$ $.001, \eta^{2}=.61$. Mean ratings revealed that participants believed reputation to be significantly more influential than the gender of the coach during the development of their expectancies. A significant main effect was also found for participant gender $\left(F_{1,302,}=11.75, p<.001, \eta^{2}=.04\right)$, indicating that there were differences between male and female athletes in the ratings of perceived influence in relation to coach gender and coach reputation. The analysis also revealed a significant interaction 
effect between coach characteristic and participant gender, $F_{1,302}=4.72, p=.03, \eta^{2}=$ .02. Follow-up one way between-groups ANOVAs indicated that while there was no significant difference between male and female athletes' ratings of the perceived influence of reputation information $\left(F_{1,302}=1.55, p=.21, \eta^{2}=.01\right)$, male athletes rated coach gender to be a significantly more influential source of information than did female athletes $\left(F_{1,302}=13.91, p<.001, \eta^{2}=.04\right)$.

INSERT FIGURE 1 HERE

\section{DISCUSSION}

The purpose of the present study was to examine the degree to which thirdparty reports (i.e., reputation) and static cues (i.e., gender) influence the expectancies of a coach's competency that are formed by athletes participating in team sports. The first hypothesis stated that reputation would influence the expectancies that athletes formed of the target coach. Specifically, it was expected that coaches with a successful reputation would be rated as more competent than coaches with an unsuccessful reputation. The first hypothesis was supported for all measures of coaching competency. In comparison to "unsuccessful" coaches, athletes expected "successful" coaches to be significantly more competent in terms of the characterbuilding of athletes, identifying and developing game-strategies, motivating athletes, and teaching relevant skills. Thus, the results of the present study support the findings of previous research $[17,18,19]$ that third-party reports (e.g., reputation) are influential sources of information that athletes use when forming expectancies of a coach.

The second hypothesis stated that coach gender would have an impact on the expectancies that athletes formed of the target coach's competency. Based on previous sport specific research that had examined the effect of gender on the coachathlete relationship [27,33], it was predicted that male coaches would be rated as 
significantly more competent than female coaches, regardless of athlete gender. The results showed that gender did have an influence on athletes' expectancies of the target coaches' competency, but only for two of the four independent variables. Male target coaches were rated as significantly more competent than female coaches in terms of their game-strategy competency and technique competency. Hypothesis two was therefore partially supported, reflecting findings from previous research $[27,33]$ that reported a tendency for male and female athletes to show a preference for male coaches.

The fact that athletes perceived the male coach to be more competent than the female coach in terms of game-strategy and technique, but not so for motivation and character-building, might be explained by considering the specific sporting context within which target coaches were evaluated by participants. Prior to providing competency ratings, participants were asked to imagine that the target coach has just been appointed as the new head coach for their team. Consequently, almost one third of participants placed the target coach in the context of coaching their soccer team. Previous studies $[28,29]$ have reported that soccer is perceived by both men and women as masculine or male-oriented. Thus, within such a context, it is feasible that athletes would expect a male coach to be more competent than a female coach when it comes to teaching soccer-specific skills (i.e., technique competency) and understanding competitive strategies specific to soccer (i.e., game-strategy competency). However, abilities such as the capacity to instil good moral attitudes (i.e., character-building competency) and enhance athletes’ self-confidence (i.e., motivation competency) are examples of coaching attributes that are not exclusive to soccer and may be applied to a range of situations and contexts. As a result, the maleoriented context of soccer may not be as salient to athletes when they are developing expectancies of a coach's motivation and character-building competency compared 
with when technique and game-strategy competency judgments are being made. However, given that other sports in addition to soccer were represented by participants in the present study (e.g., rugby union, basketball, cricket, field hockey), the findings indicate that soccer may not be the only sport perceived by male and female athletes to be masculine and male-oriented. Further research is warranted in order to provide evidence that either supports or refutes this tentative contention.

The third hypothesis predicted that both male and female athletes would perceive the influence of reputation on their expectancies of the coach to be greater than that of coach gender. The results obtained from athletes' ratings of the perceived influence of each of the dependent variables on the development of their expectancies showed that reputation information was perceived to be significantly more influential than the static cue of coach gender. Furthermore, the larger effect size for reputation, accompanied by the fact that gender was only shown to impact on expectancies related to two of the four elements of coaching competency (i.e., technique competency and game-strategy competency) support the findings of Manley et al. [17], which suggested that third-party reports such as reputation information exert more power over athletes' expectancies than do static cues such as knowledge of coaches' gender. Thus, hypothesis three was supported.

The results reported by Manley et al. [17] also indicated that there were no gender differences in terms of the cues that athletes deem to be most influential during the expectancy formation process. This is counter to the results of the present study, which revealed that while both male and female athletes deemed reputation to be significantly more influential than coach gender when forming initial expectancies of a coach, the degree to which gender was perceived as influential differed significantly as a function of athlete gender. Male participants perceived coach gender to have more of an impact on their expectancies of a coach than did female athletes. One 
possible explanation is that female athletes, through their own experiences and involvement in sport, are encouraged to challenge the traditional stigmas associated with female sport participation more readily than male athletes, thus perceiving informational cues such as coach gender to be less indicative of coaching competency. As a result, this finding might only be applicable to coach gender rather than static cues in general. However, a limitation of the present study is that it failed to control for athletes' previous experience of working with male and female coaches. Thus, similar research which accounts for athletes' levels of prior exposure to male and female coaches is clearly warranted.

The findings of the present study provide a unique contribution to the expectancy effect literature. This is the first time that a study has investigated the impact of coach reputation and coach gender on the expectancies that athletes form of a coach’s competency and ability. Moreover, the findings have important implications for coaching practise and the development of positive coach-athlete relationships. Building on the suggestions highlighted following the explorative findings of Manley et al. [17], the present study highlights some important implications for coaches, particularly in relation to the expectancies formed by athletes when they are evaluating a new coach. Since reputation seems to have an effect on athletes' cognitive responses to a coach they are expected to work with, it is suggested that coaches and their employers utilise this fact to their advantage (e.g., by placing emphasis on positive aspects of coach's reputation prior to his/her first meeting with athletes).

By maximising the positive reputation information that athletes receive about a coach, the chances of developing positive coach-athlete relationships may be enhanced as a result of the initial positive expectancies that athletes are more likely to form about the coach in response to such information. Hence, reputation information 
may help to ensure that coaches are better equipped to overcome the barriers to forging a good working relationship with his or her new team. However, the present study only examined the impact of successful and unsuccessful reputation information on athlete expectancies of coaching ability. Future research should investigate the effects of the presence and absence of reputation information, as well as examining the effects of other forms of reputation information (e.g., coaching experience, playing experience). Such investigation would provide a greater understanding of the extent to which reputation information influences athletes' expectancies of coaches, and also reveal whether or not there are differences in the strength of the effect on athletes’ expectancies between the various types of reputation information. Furthermore, research of this kind would indicate the degree to which coaches and their employers should be aware of the amount of reputation information they disclose to athletes.

According to the results of the present study, female coaches are at a disadvantage compared with male coaches in terms of their ability to elicit positive responses from the athletes they are asked to work with. This is not a surprising finding, given previous work that has highlighted the consensus between male and female athletes concerning their preference for being coached by men rather than women $[27,33]$. However, the athletes' perception that coach gender is not as influential a factor as reputation in the development of their expectancies of coaches does not conceal the fact that coach gender still had an influence on athletes’ expectancies of coaching competency. This finding has several possible explanations. As alluded to earlier, athletes’ prior experience of working with male and/or female coaches may have impacted on the extent to which coach gender was perceived to be a salient source of information. Alternatively, participants may have been motivated by social desirability in their responses to the perceived influence questions [45], or 
they may simply have been unaware of their cue usage during expectancy formation [46]. Any attempt to suggest which of these effects has occurred within the present study would be purely speculative. Thus, future research using experimental techniques designed to account for unconscious information processing (e.g., Implicit Association Test) [47] would be a worthwhile extension of the present study. Moreover, in displaying the target coach, future research should use dynamic stimuli (e.g., video footage) rather than static photographs in order to ensure that the wide range and volume of information presented to athlete participants is as close as possible to that witnessed during naturalistic situations.

The reported effects of reputation information on athletes' predictions of coaching competency imply that the impressions and expectancies a coach wishes to instil in his or her athletes are influenced by factors that can, to a certain extent, be controlled by the target. Female coaches and their employers should ensure that positive information such as a successful reputation is made available to athletes (where possible) early in the coach-athlete relationship in order to try and harness the positive expectancy effects that may override the impact of negative expectancies that might be developed based on coach gender. Future research should aim to identify the reasons why athletes form less positive expectancies of female coaches as opposed to male coaches. If such expectancies are based on traditional sex-role stereotypes regarding female participation in sport [28,29], then possible changes in public opinion regarding these stereotypes and a greater acceptance of females in sport [30,31,32] may lead to changes in athletes’ expectancies of female coaches. Thus, longitudinal studies which aim to monitor the public's attitudes to females in sport and identify changes in these attitudes are warranted.

Following on from previous research that has investigated expectancy formation within the coach-athlete relationship [12,17,20], the present study examined 
how athletes form expectancies of coaches, and identified some informational cues that influence the expectancy formation process. Subsequent research now needs to investigate the impacts of these expectancies. Specifically, the cognitive, affective, and behavioural consequences of athletes' expectancies of coaches require direct examination.

\section{References}

1. Olson, J.M., Roese, N.J., and Zanna, M.P., Expectancies, in: E.T. Higgins and A.W. Kruglanski (Eds.), Social Psychology: Handbook of Basic Principles, The Guildford Press, New York, 1996, 211-238.

2. Miller, D.T. and Turnbull, W., Expectancies and Interpersonal Processes, $\underline{\text { Annual }}$ Review of Psychology, 1986, 37, 233-256.

3. Darley, J.M., and Fazio, R.H., Expectancy Confirmation Processes Arising in the Social Interaction Sequence, American Psychologist, 1980, 35, 867-881.

4. Franks, I.M., and Hanvey, T., Cues for Goalkeepers: High-tech Methods Used to Measure Penalty Shot Response, Soccer Journal, 1997, 42, 30-33.

5. Jowett, S., and Poczwardowski, A., Understanding the Coach-Athlete Relationship, in: S. Jowett and D. Lavallee (Eds.), Social Psychology in Sport, Human Kinetics, Champaign, IL, 2007, 3-14.

6. Becker, A.J., It's Not What They Do, It's How They Do It: Athlete Experiences of Great Coaching, International Journal of Sports Science and Coaching, 2009, 4, 93119.

7. Horn, T.S., Expectancy Effects in the Interscholastic Athletic Setting:

Methodological Considerations, Journal of Sport Psychology, 1984, 6, 60-76.

8. Rejeski, W., Darracott, C., and Hutslar, S., Pygmalion in Youth Sport: A Field Study, Journal of Sport Psychology, 1979, 1, 311-319. 
9. Sinclair, D.A., and Vealey, R.S., Effects of Coaches’ Expectations and Feedback on the Self-perceptions of Athletes, Journal of Sport Behavior, 1989, 12, 77-91.

10. Solomon, G.B., DiMarco, A.M., Ohlson, C.J., and Reece, S.D., Expectations and Coaching Experience: Is More Better?, Journal of Sport Behavior, 1998, 21, 444-455.

11. Solomon, G.B., Expectations and Perceptions as Predictors of Coaches’ Feedback in Three Competitive Contexts, Journal for the Study of Sports and Athletics in Education, 2008, 2, 161-179.

12. Becker, A.J., and Solomon, G.B., Expectancy Information and Coach

Effectiveness in Intercollegiate Basketball, The Sport Psychologist, 2005, 19, 251266.

13. Horn, T.S., Lox, C., and Labrador, F., The Self-fulfilling Prophecy Theory: When Coaches’ Expectations Become Reality, in: J.M. Williams (Ed.), Applied Sport Psychology: Personal Growth to Peak Performance, $6^{\text {th }}$ edn, McGraw-Hill, Boston, MA, 2010, 81-105.

14. Solomon, G.B., The Assessment of Athletic Ability in Intercollegiate Sport: Instrument Construction and Validation, International Journal of Sports Science and Coaching, 2008, 3, 513-525.

15. Smoll, F.L., and Smith, R.E., Leadership Behaviours in Sport: A Theoretical Model and Research Paradigm, Journal of Applied Social Psychology, 1989, 19, $1522-1551$.

16. Horn, T.S., Coaching Effectiveness in the Sports Domain, in: T.S. Horn (Ed.), Advances in Sport Psychology, $3^{\text {rd }}$ edn, Human Kinetics, Champaign, IL, 2008, 239267.

17. Manley, A.J., Greenlees, I., Graydon, J., Thelwell, R., Filby, W.C.D., and Smith, M.J., Athletes’ Perceptions of the Sources of Information Used When Forming Initial Impressions and Expectancies of a Coach, The Sport Psychologist, 2008, 22, 73-89. 
18. Findlay, L.C., and Ste-Marie, D.M., A Reputation Bias in Figure Skating, Journal of Sport \& Exercise Psychology, 2004, 26, 154-166.

19. Jones, M.V., Paull, G.C., and Erskine, J., The Impact of a Team’s Aggressive Reputation on the Decisions of Association Football Referees, Journal of Sports Sciences, 2002, 20, 991-1000.

20. Solomon, G.B., and Rhea, D.J., Sources of Expectancy Information Among College Coaches: A Qualitative Test of Expectancy Theory, International Journal of Sports Science and Coaching, 2008, 3, 251-268.

21. Cook, M., Interpersonal Perception, Penguin Education, Middlesex, 1971.

22. Jussim, L., Accuracy in Interpersonal Expectations: A Reflection-Construction Analysis of Current and Classic Research, Journal of Personality, 1993, 61, 637-668. 23. Coulomb-Cabagno, G., Rascle, O., and Souchon, N., Players’ Gender and Male Referees’ Decisions About Aggression in French Soccer: A Preliminary Study, $\underline{\text { Sex }}$ Roles, 2005, 52, 547-553.

24. Jowett, S., Frost, T., and Timson-Katchis, M., Race/Ethnicity in the All Male Coach-Athlete Relationship: Black Footballers’ Narratives, Poster Presentation at BPS Annual Conference, City Hall, Cardiff, 2006.

25. Lubker, J.R., Watson II, J.C., Visek, A.J., and Geer, J.R., Physical Appearance and the Perceived Effectiveness of Performance Enhancement Consultants, The Sport Psychologist, 2005, 19, 446-458.

26. Thelwell, R.C., Weston, N.J.V., Greenlees, I.A., Page, J.L., and Manley, A.J., Examining the Impact of Physical Appearance on Impressions of Coaching Competence, International Journal of Sport and Exercise Psychology, in press.

27. LeDrew, J.E., and Zimmerman, C., Moving Towards an Acceptance of Females in Coaching, The Physical Educator, 1994, 51, 6-14. 
28. Csizma, K.A., Wittig, A.F., and Schurr, K.T., Sport Stereotypes and Gender, Journal of Sport \& Exercise Psychology, 1988, 10, 62-74.

29. Koivula, N., Ratings of Gender Appropriateness of Sports Participation: Effects of Gender-based Schematic Processing, Sex Roles, 1995, 33, 543-557.

30. Riemer, B.A., and Visio, M.E., Gender Typing of Sports: An Investigation of Metheny’s Classification, Research Quarterly for Exercise and Sport, 2003, 74, 193204.

31. Fasting, K., and Pfister, G., Female and Male Coaches in the Eyes of Female Elite Soccer Players, European Physical Education Review, 2000, 6, 91-110.

32. Sherman, C.A., Fuller, R., and Speed, H.D., Gender Comparisons of Preferred Coaching Behaviours in Australian Sports, Journal of Sport Behavior, 2000, 23, 389406.

33. Kontos, A., Cross-gender Perceptions of Coaching Behaviours. Proceedings of 2003 NASPSPA Annual Conference, Journal of Sport \& Exercise Psychology, 2003, 25, S82-S83.

34. Tabachnick, B.G., and Fidell, L.S., Using Multivariate Statistics, $5^{\text {th }}$ edn, Allyn \& Bacon, Boston, MA, 2007.

35. Field, A., Discovering Statistics Using SPSS, $3^{\text {rd }}$ edn, Sage, London, 2009.

36. Johnson, D.L., Hallinan, C.J., and Westerfield, R.C., Picturing Success:

Photographs and Stereotyping in Men’s Collegiate Basketball, Journal of Sport Behavior, 1999, 22, 45-53.

37. Greenlees, I., Webb, H., Hall, B., and Manley, A., Curmudgeon or Golden-ager?: Reported Exercise Participation Influences the Perception of Older Adults, Journal of Sport \& Exercise Psychology, 2007, 29, 333-347.

38. Feingold, A., Good-looking People Are Not What We Think, Psychological Bulletin, 1992, 111, 304-341. 
39. Furnham, A., Petrides, K.V., and Temple, J., Patient Preferences for Medical Doctors, British Journal of Health Psychology, 2006, 11, 439-449.

40. Myers, N.D., Feltz, D.L., Maier, K.S., Wolfe, E.W., and Reckase, M.D., Athletes'

Evaluations of Their Head Coach’s Coaching Competency, Research Quarterly for

Exercise and Sport, 2006, 77, 111-121.

41. Myers, N.D., Wolfe, E.W., Maier, K.S., Feltz, D.L., and Reckase, M.D., Extending Validity Evidence for Multidimensional Measures of Coaching

Competency, Research Quarterly for Exercise and Sport, 2006, 77, 451-463.

42. Stevens, J.P., Applied Multivariate Statistics for the Social Sciences, $4^{\text {th }}$ edn, Lawrence Erlbaum, Mahwah, NJ, 2002.

43. Clark-Carter, D., Doing Quantitative Psychological Research: From Design to Report, Psychology Press, Hove, 1997.

44. Maxwell, S., When to Use MANOVA and Significant MANOVAs and Insignificant ANOVAs or Vice Versa, Journal of Consumer Psychology, 2001, 10, 29-30.

45. Guyll, M., and Madon, S., Trait Hostility: The Breadth and Specificity of Schema Effects, Personality and Individual Differences, 2003, 34, 681-693.

46. Chen, M., and Bargh, J.A., Nonconscious Behavioural Confirmation Processes: The Self-fulfilling Consequences of Automatic Stereotype Activation, Journal of Experimental Social Psychology, 1997, 33, 541-560.

47. Greenwald, A.G., McGhee, D.E., and Schwartz, J.K.L., Measuring Individual Differences in Implicit Cognition, Journal of Personality and Social Psychology, 1998, 74, 1464-1480. 


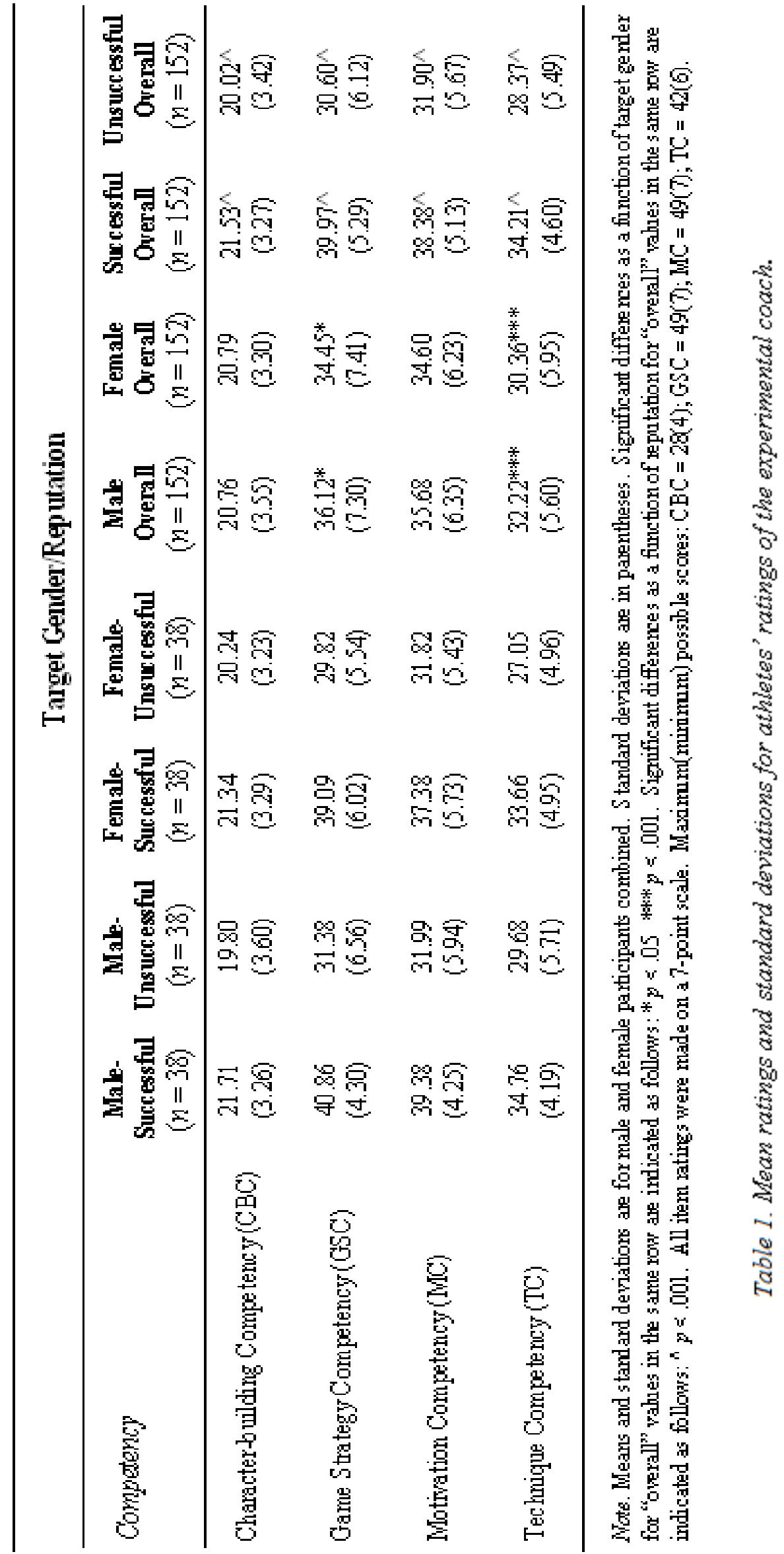




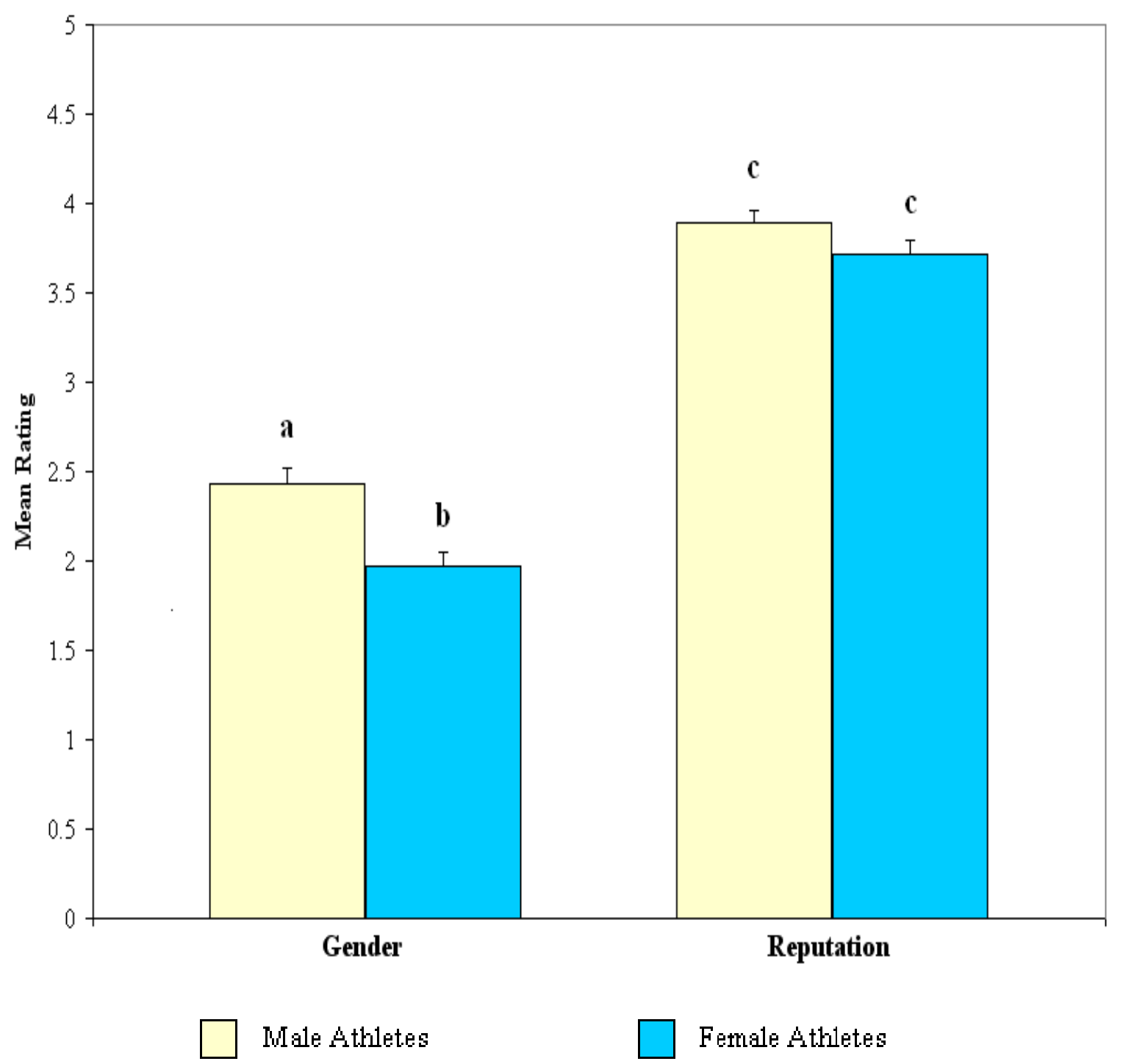

Note: Columns not sharing a common letter are significantly different $(p<.001)$

Figure 1. Male and female athletes' mean ratings of the perceived influence of gender and reputation. 